\title{
Como ser Corpo Místico e ASSEMBLEIA LITÚRGICA NA PÓS PANDEMIA ${ }^{1}$
}

\author{
Prof. Dr. Andrea Grillo*
}

DOI: https://doi.org/10.52451/teopraxis.v37i129.7

Recebido: 12 de janeiro de 2019| Aprovado: 26 de junho de 2019

Resumo: O presente texto quer refletir sobre o enunciado no título que me foi proposto, isto é, quero colocar em relação ou em contraposição os termos "corpo místico" e "assembleia litúrgica", bem como "assembleia celebrante", que muito tem criado confusão, argumentação sem plausibilidade e até confrontos em modos diferentes de pensar. Com a fundamentação de documentos oficiais da Igreja vamos procurar refletir sobre estes termos, relacionados ao contexto que estamos vivendo, sobretudo o da pandemia, provocando o isolamento social e, desta forma, o fechamento de muitas atividades, inclusive as da Igreja, sobretudo àquelas relacionadas às celebrações litúrgicas.

Palavras-chave: Corpo Místico. Assembleia Litúrgica. Igreja. Assembleia celebrante. Pandemia.

\section{Introdução}

O título, com a sua bela formulação, nos motiva a uma reflexão em três níveis, que se torna importante justamente porque coloca em correlação "mundos" que, vistos de outras formas, os teríamos precisamente separados: isto significa que devemos refletir sobre a tradição da Igreja, que se auto-

1 Texto original em italiano. Tradução do Pe. Clair Favreto, doutor em Liturgia Pastoral pelo Instituto de Liturgia Pastoral da Abadia de Santa Giustina, de Pádua. É professor de Liturgia e Sacramentos na Itepa Faculdades.

* É filósofo e teólogo italiano, leigo, especialista em liturgia e pastoral. Doutor em teologia pelo Instituto de Liturgia Pastoral, de Pádua. Professor do Pontifício Ateneu Santo Anselmo, de Roma, do Instituto Teológico Marchigiano, de Ancona, e do Instituto de Liturgia Pastoral da Abadia de Santa Justina, de Pádua. Também é membro da Associação Teológica Italiana e da Associação dos Professores de Liturgia da Itália. Enail: grilloreba@gmail.com 
interpreta como "corpo místico", em relação à outra definição, e até diferente, definida como "assembleia litúrgica", para considerar que ela é mais do que um simples "ornamento cerimonial"; e tudo isto devemos pensar nas condições de póspandemia, ou seja, depois de uma passagem impressionante que, do ponto de vista humano e teológico, é exigente e que forçou a todos nós, por razões extra-eclesiais e extra-litúrgicas, a uma reflexão radical sobre a identidade humana e cristã e, portanto, também sobre a liturgia e o culto cristão.

Confrontam-se aqui "três linguagens", que pertencem a diferentes experiências e formas expressivas, o que não é fácil de intregrá-las e harmonizá-las. Gostaria de mostrar brevemente a complexidade deste entrelaçamento, que a condição de pandemia de alguma forma acentuou. E, justamente por esse motivo, nos forçou a repensá-las com profundidade, a buscar sua raiz primeira e a nos reconciliar com a nossa história e a nossa tradição. Por isso, gostaria, antes de tudo, analisar as "três palavras-chave" do título para, depois, procurar integrá-las numa visão unitária, que nos apontará uma mudança de rumo, uma revisão das expressões, para obter uma experiência eclesiástica mais profunda e autêntica, mesmo fazendo memória de textos fundamentais, que frequentemente parecem ter sido esquecidos.

\section{Três expressões/palavras}

As três terminologias relacionadas nascem de perspectivas e preocupações parcialmente sobrepostas. Vamos analisar, brevemente, cada uma:

\section{a) A Igreja como Corpo Místico}

Antes de Pio XII dedicar uma encíclica completa ao tema Corpo Místico, em 1943, o termo já havia se tornado assunto há 
algumas dezenas de anos, a partir de um significado "político" muito potente. Como lemos na Vehementer $\operatorname{Nos}^{2}(\mathrm{VN})$, com a qual Pio X em 1906 comenta de maneira dolorosa as leis francesas de separação entre Igreja e Estado, o termo é usado de forma decididamente política:

"A Sagrada Escritura nos ensina, e a tradição dos Padres nos confirma, que a Igreja é o Corpo Místico de Jesus Cristo, um Corpo regido por Pastores e Doutores; ou seja, uma sociedade de homens no seio da qual há lideranças que tem plenos e perfeitos poderes para governar, para ensinar e para julgar (Matt. XXVIII, 18-20; XVI, 18-19; XVIII, 18; Tit. II, 15; II Cor. X, 6; XIII, 10). Daí resulta que a Igreja é, por sua natureza, uma sociedade desigual, isto é, uma sociedade formada por duas categorias de pessoas: os Pastores e o Rebanho, os que ocupam uma posição entre os diferentes graus da hierarquia, e a multidão dos fiéis. $\mathrm{E}$ essas categorias são tão distintas entre si, que apenas no corpo pastoral residem a lei e a autoridade necessária para promover e dirigir todos os membros para as finalidades sociais; e que a multidão não tem outro dever a não ser de se deixar conduzir e, como rebanho dócil, de seguir os seus Pastores" (VN 22).

A expressão "corpo místico" se imbuiu de "sentido político" quando assumiu a tarefa de decidir a relação entre Igreja, mundo e história de forma radical. Neste sentido, usa o termo absolutidez e não democracia, usa o termo autoridade e não liberdade, pensa no povo de Deus como "rebanho" e a Igreja como "sociedade sem igual".

A retomada, em 1943, por parte de Pio XII, em um contexto mais amplo e dramático, acrescenta outros temas, mas não perde esse "núcleo institucional" da definição. Corpo místico é, ao mesmo tempo, uma definição teológica e sociológica da Igreja: indica nele a referência "soberana" da autoridade, em relação à qual é difícil conceber uma

2 Carta Encíclica VEHEMENTER NOS - sobre as relações entre a Igreja e o Estado, de Pio X, publicada em 11.02.1906. 
"autonomia das realidades seculares". Assim, no termo "corpo místico', ao mesmo tempo em que acrescenta a dimensão sacramental, tende a prevalecer um perfil institucional que durante a "pandemia" procurou fazer uma leitura do contágio, do confinamento, da distância, como uma "perda de poder". E, às vezes, tanto fora como dentro da Igreja, houve reações de modo desproporcionado, inclusive a respeito do próprio texto da Igreja.

\section{b) A Igreja como assembleia litúrgica}

Diferente é a linguagem da "assembleia litúrgica", do "povo de Deus”, da redescoberta da centralidade da celebração litúrgica. A origem dessa expressão é ao mesmo tempo "mais antiga" (do ponto de vista bíblico) e mais moderna, pois é um dos frutos do Movimento Litúrgico e do Concílio Vaticano II (1962-1965). Neste caso, a pandemia não coloca em questão a "autoridade da Igreja" e sua "soberania”, mas a sua linguagem mais delicada e primitiva, mais elementar e mais profunda. A impossibilidade de reunir a "assembleia litúrgica" se torna, a este respeito, um grave limite para a experiência de comunhão eclesial. Assembleias impossibilitadas, ou limitadas nos gestos, movimentos, cantos, alteraram o "âmago eclesial” e a possibilidade de "presença" nas realidades humanas e sociais. Por essa razão, uma reflexão sobre o impacto da pandemia para a Igreja tomou esse perfil cultual e litúrgico de modo central. Muitas vezes, porém, a "autoridade da Igreja" foi identificada com a possibilidade de "propor atos de culto", sem considerar minimamente que a Igreja nem tanto "se designa a si mesma" no seu ato de culto, mas, sobretudo, "se revela" à ação da graça de Deus. De fato, ao celebrar, a Igreja nem tanto "ganha poder', mas "perde poder". Ao invés, esta passagem do senhorio para a liturgia, muitas vezes pareceu, como veremos, muito rápida e imediata. Pouco meditada. 


\section{c) A Igreja na circunstância da pandemia}

De grande interesse é o fato de que, durante a pandemia, as duas perspectivas que indicamos - ou seja, a natureza de "corpo místico" e a de "assembleia litúrgica" - foram usadas numa relação complexa, frequentemente problemática ou até mesmo competitiva. O que quero dizer com esta observação? Que diante da confusão causada pela epidemia tão incerta e tão potente, que levou à tomada de medidas de isolamento e de cuidado muito drásticas na esfera civil, a Igreja experimentou uma forte crise de identidade, uma vez que viu suas "funções litúrgicas" reduzidas ou até mesmo impedidas. Para sair desta restrição, não é comum, mas foram usados argumentos muito redutivos e perigosos para um desenvolvimento integral e equilibrado da parte prática (pastoral). Por um lado, de fato, havia a tentação de "incumbir-se" numa visão de "corpo místico" garantido exclusivamente pela hierarquia. Parece que a hierarquia ganhou uma margem de "operatividade ritual" mesmo ao custo de celebrar apenas de forma privativa - a Igreja pode ser salva! Por outro lado - e este é o outro extremo das reações - houve um total desejo de identificar a Igreja com as próprias "ações rituais" a ponto de sentir como que uma "afronta violenta" em cada tentativa de justificar a limitação dos contatos, dos espaços, dos movimentos. Talvez tudo isso tenha sido possível desde que fosse esquecido o rico e complexo caminho que nos levou a essas novas evidências. Vamos tentar recordar brevemente este recente caminho histórico.

\section{O caminho de crescimento "após o Concílio Vaticano II"}

As difíceis relações com a história, que sempre caracterizaram a vida da Igreja, permitiram desenvolver categorias de mediação através das quais a Igreja interpretou sua identidade em relação a Deus e ao mundo. Os termos "corpo 
místico" e "assembleia litúrgica” foram usados para o mesmo fim, mas com intenção e referências muito diferentes. Mesmo diante da pandemia, era comum que a ênfase mais acentuada se voltasse para a instância do "corpo místico", na qual se presume uma visão de Igreja e de mundo que o Concílio Vaticano II queria explicitamente superar.

A pandemia, desta forma, - usando a metáfora das "máscaras" em nossos rostos - deixou cair muitas destas máscaras. As mesmas máscaras com as quais buscamos principalmente uma "identidade perene" do corpo da Igreja e que, muitas vezes, a identificamos com as imagens do século XVIII, isto é, de forma intransigente, infalível, como "sociedade sem igual".

A Igreja deve preservar sua própria "diferença”. Ai se não a fizer! Mas as categorias com as quais ela guia a esse propósito na história, nem sempre foram as mesmas. Diante da "crise da pandemia", uma prova de "responsabilidade" e de "colaboração" com as autoridades civis, por parte da Igreja, não é em si uma indicação de uma "perda de relevância". Uma "estilização de ritos" - temporânea e até dolorosa - pode ser a passagem obrigatória para uma Igreja que realmente quer ser o corpo de Cristo, místico e real. A tentação de identificar "corpo místico" e "rito tridentino" ainda permanece forte, e provém também dos ambientes que nunca pensamos que ainda poderiam ser assim tão atrasados, não apenas teologicamente, mas também pastoralmente, isto é, também na maneira de celebrar.

\section{O desafio para o futuro}

$\mathrm{O}$ que podemos esperar para o nosso futuro? Eu diria, claramente, pelo menos três aspectos:

a) Estávamos todos despreparados e reagimos como podíamos. Onde os Estados foram solícitos pelo bem comum, mesmo tomando medidas drásticas para restringir a livre 
circulação de pessoas, permitiram salvar vidas. Não se deve esquecer que isso só é possível com base num "certo nível de estado social". Até mesmo o "fechamento das Igrejas" pode ocorrer por meio de uma "solicitação social", e até de forma intensa, encontrando, inclusive, meios à sua disposição para fazê-lo. Seria grave se a Igreja olhasse apenas para a "própria" liberdade e negligenciasse o bem comum.

b) A suspensão das celebrações ou até mesmo a sua limitação constituem, no entanto, uma "ferida" à ação normal da Igreja. A ferida não é “devida a alguém”, não é um erro que alguém faz à Igreja, mas é o resultado de decisões pensadas que podem e devem ser aceitas. Mesmo assim, elas fazem sofrer o corpo da Igreja que, para viver, precisa da palavra celebrada e do sacramento compartilhado.

c) Precisamente esta "condição de minoria" pode abrir espaços incríveis de recuperação no "pós-covid”. Se e quando for, poderemos e deveremos voltar às nossas "ações rituais" com toda a riqueza de um "desejo não realizado" - de linguagem verbal e não verbal - que finalmente tomará forma, figura, estrutura e força. Poderá ser útil lembrar que somente sendo "plenamente" assembleia celebrante, daremos forma ao "corpo de Cristo", ao "corpo do Ressuscitado" que é o "corpo místico".

\section{Algumas verdades esquecidas que precisam ser redescobertas}

A diferença entre o "estado de exceção" relacionado à persistência de estilos tridentinos e ao projeto do Concílio Vaticano II nos permitirá, um belo dia, dizer que "o estado de exceção acabou”. Podemos e deveremos voltar à lógica conciliar. Portanto, o "isolamento social" - com todo o sofrimento humano e comunitário que provoca - faz surgir duas lógicas opostas e antitéticas. Colabora para uma "igreja exclusivamente de padres" (e de padres exclusivos) e também 
remete à iniciativa dos fiéis não clérigos e não masculinos. Em particular, emerge, ao mesmo tempo:

- a tentativa de apoiar uma "igreja de emergência de apenas padres celebrantes", que se baseia em documentos e cânones do início da modernidade e pré-conciliares;

- a tentativa de justificar o papel da assembleia, de uma ministerialidade ampliada e do papel das mulheres, que implica a retomada de discursos profundos e decisivos sobre essas questões.

Tudo isso requer uma desclericalização radical e urgente, que possa dizer três questões decisivas, não de fato novas, mas que é urgente dizer de um modo novo.

a) Que a assembleia celebrante é o Corpo de Cristo ressuscitado (e, portanto, não pode ser de algum modo pensada ou considerada apenas acessória);

b) Que a assembleia precisa de "múltiplos ministérios", não apenas a presidência do presbítero;

c) Que as mulheres possam exercer funções de autoridade, porque podem e devem ser reconhecidas como titulares de um ministério num sentido íntegro e pleno, de um ministério verdadeiro e não apenas de enfeite. Nas mulheres está implicado e expressado o anúncio apostólico, do qual depende a mesma tradição eclesiástica na sua verdade plena.

Esse caminho, pois, é difícil e, teologicamente, também é muito exigente. Poderá colocar definitivamente no sótão aqueles discursinhos clericais, bem selados em tristes autoindicativos, onde ficam radiantes em citar as frases de homens certamente geniais, mas que viveram na época das invasões bárbaras ou do feudalismo, e ficam negociando e compartilhando acordos institucionais sem os terem escolhido, mas como se fossem evangelho ou, ainda pior, como se fossem "de direito divino".

São as artimanhas típicas de uma igreja que não existe mais e 
que fica bem apenas "a portas fechadas". Porque há uma Igreja que sempre esteve "de portas fechadas" mesmo quando as portas estavam bem abertas. Uma Igreja que ficou fechada em condutas antigas, em palavras antigas, em fórmulas antigas. $\mathrm{E}$ justamente agora ela se vê melhor porque realiza, plenamente, a si mesma, graças à epidemia. E também realiza isso com uma ingenuidade simples e, às vezes, com uma arrogância sem pudor.

Mas não há só isso. Há, também, e bem viva, uma Igreja que precisa urgentemente recuperar os grandes discursos, que a oficialidade eclesial teve a força de fazer abertamente e solenemente há 60 anos atrás e que hoje parece tão confusa quando tem que repeti-los de forma credível. Há, porém, aqueles que o sabem fazer. E se encontra justamente naquele ponto alto da pirâmide que está de forma invertida ${ }^{3}$. Precisamente por causa dessa condição invertida, muito antes da atual pandemia que desertifica o mundo, mesmo quando o Papa Franciso ainda saía no meio da multidão festiva, numa Praça de São Pedro aberta, ele já havia aparecido gigantemente sozinho, buscando viver numa igreja de portas abertas, mesmo que ela preferisse continuar de portas fechadas. É aquela mesma Igreja que se revitaliza hoje, que se permite fazer sem o povo, se permite o substituir em tudo, por meio de um carimbaço ou de um decreto. Se tivermos a paciência para ler os discursos escritos nas últimas semanas por muitos dos que estão em contatos próximos com esta cúpula da pirâmide de forma

3 Segundo o teólogo Andrea Grillo, a forma invertida quer significar que quanto maior e mais alto grau é o ministério, tanto mais na base deve estar. Ele entende que todo o ministério deve ser colocado a serviço. $O$ verdadeiro ministério, principalmente o do alto da pirâmide, deve estar embaixo, na base. Por isso usa a expressão pirâmide invertida (rovesciata), literalmente virada, de cabeça para baixo. É uma inspiração do Papa Francisco que insistentemente pede uma Igreja de comunhão, do serviço, da sinodalidade. De cabeça para baixo significa que o vértice se encontra abaixo da base e desta obtém a sua autoridade, uma autoridade que se coloca a serviço. 
invertida, não é difícil reconhecer que essa condição paradoxal de afastamento dobrou: o fechamento civil, duplicado pelo fechamento da Igreja. As portas fechadas da Igreja, porém, abrem uma dupla responsabilidade, extraordinariamente complexa: aqueles que podem estar na igreja, procurem estar de forma diferente. Aqueles que na Igreja não podem estar, que saibam ser igreja em outro lugar e de forma diferenciada.

\section{a) O mínimo episcopal de teologia eucarística}

Para ambas as categorias de sujeitos, não doi nada fazer um retorno a uma das fontes decisivas do entendimento eucarístico comum. O uso dos termos mais apropriados é, muitas vezes, o primeiro sinal de um estilo eclesial e de um método confiável. O texto normativo oficial, ao descrever a experiência de "celebração eucarística", nunca usa o termo "missa sem povo". O "esquema" usado pela Instrução Geral do Missal Romano (IGMR) 3 $3^{\text {a }}$ edição, para falar das diferentes "formas" de celebração eucarística, é o seguinte:

- Missa com o povo;

- Missa concelebrada;

- Missa com a presença de apenas um ministro.

Isso acontece porque a IGMR sabe que a missa não pode ser celebrada "privativamente", mesmo que seja o Papa. A missa é, antropológica e eclesialmente, um evento plural e comunitário. Humanamente, nunca inicia de " 1 ", isto é, de uma pessoa somente, mas pelo menos de " 2 ", de uma elementar comunidade. Esta é a mesma sabedoria que permanece escrita também no Código de Direito Canônico, quando no cânone 906 se encontra o seguinte: "O sacerdote não celebre o Sacrifício Eucarístico sem a participação de pelo menos alguns fiéis, se não por justa e razoável causa”.

Quando são feitas essas afirmações com tanta precisão, é colocado acima de tudo o valor da "celebração comunitária” e 
se usa o termo "caso de necessidade" apenas como uma exceção, mesmo sendo dolorosa e difícil. A sabedoria teológica se encontra justamente em perceber e comunicar essas diferenças, tão sutis quanto um fio de cabelo, mas tão decisivas para a vitalidade da Igreja.

\section{b) A Missa não é o "joguinho da torre ${ }^{4}$ "}

A compreensão profunda de um necessário "sentido litúrgico e pastoral" pode ser lida nos números 91-96 da $\mathrm{IGMR}^{5}$. Vejamos o primeiro número:

"A Celebração eucarística constitui uma ação de Cristo e da Igreja, que é o "sacramento da unidade", isto é, do povo santo, unido e ordenado sob a direção do Bispo. Por isso, pertence a todo o Corpo da Igreja, e o manifesta e afeta; mas atinge a cada um dos seus membros de modo diferente, conforme a diversidade de ordens, ofícios e participação atual. Dessa forma, o povo cristão, "geração escolhida, sacerdócio real, gente santa, povo de conquista", manifesta sua organização coerente $e$ hierárquica. Todos, portanto, quer ministros ordenados, quer fiéis leigos, exercendo suas funções e ministérios, façam tudo e só aquilo que lhes compete" (IGMR 91).

Dizer que a missa "pertence a todo o Corpo da Igreja" é a visão mais profunda, sem qualquer "competição" entre os sujeitos, o que inverteria o próprio sentido da eucaristia. Cada um é sujeito. A lógica nunca é aquela que distingue entre livre e submisso. Seria um erro no uso das "categorias". É como se fosse aceitar a lógica do joguinho da torre, jogo clássico e perverso: "na missa, quem é jogado da torre? o padre ou a assembleia?

4 É uma brincadeira em que as crianças montam uma torre feita de cubos de madeira ou de plástico com tamanhos diferentes, às vezes enumerados. $\mathrm{O}$ jogo consiste em derrubar da torre os cubos sem deixá-la cair. Por fim cai também a torre.

$5 \mathrm{Na}$ Instrução Geral sobre o Missal Romano para o Brasil, n.58-62. 
A mesma lógica "inclusiva" a encontramos na referência dedicada ao presbítero (IGMR 93), na qual a autoridade de presidência está relacionada ao serviço a Deus e ao povo. Não se usa as categorias de objetivo/subjetivo, mas aquelas de "serviço a Deus e ao povo". Este serviço não pode ser separado, no sentido que assim, como não se pode servir o povo sem servir a Deus, também não se pode servir a Deus, sem servir o povo: a "oferta do sacrifício" se torna presente no "presidir o povo reunido".

\section{c) Temos vergonha, talvez, de dizer "assembleia celebrante"?}

A resposta pode ser encontrada na brilhante e articulada definição da função do "ministro da assembleia". Aqui seria interessante e oportuno recuperar, por parte de todos os fiéis e ministros da Igreja, a força desses textos, sem se distrair com documentos gravemente enganosos que tinham a ousadia de pedir "cautela" no uso da categoria de "assembleia celebrante". Às vezes, de forma imprudente, essas lógicas apologéticas de "combate aos abusos", impedem de pensar com "ternura" a respeito das dinâmicas da Igreja. Os bispos e os presbíteros devem ter isso bem claro, pois "presidem uma assembleia que celebra”. O ato de celebrar é constitutivamente plural e comunitário. Para isso, retomamos o que nos diz a IGMR 95-96:

"Na celebração da Missa os fiéis constituem o povo santo, o povo adquirido e o sacerdócio régio, para dar graças a Deus e oferecer o sacrifício perfeito, não apenas pelas mãos do sacerdote, mas também juntamente com ele, e aprender a oferecer-se a si próprios. Esforcem-se, pois, por manifestar isto através de um profundo senso religioso e da caridade para com os irmãos que participam da mesma celebração. Por isso, evitem qualquer tipo de individualismo ou divisão, considerando sempre que todos tem um único Pai nos céus e, por este motivo, são todos irmãos entre si" (IGMR 95) ${ }^{6}$.

6 Na versão português Brasil, n.62. 
"Formem um único corpo, seja ouvindo a Palavra de Deus, seja tomando parte nas orações e no canto ou, sobretudo, na oblação comum do sacrifício e na comum participação da mesa do Senhor. Tal unidade se manifesta muito bem quando todos os fieis realizam em comum os mesmos gestos e assumem as mesmas atitudes externas" (IGMR 96) ${ }^{7}$.

Estes parágrafos evidenciam o "espírito da Igreja” desta arejada apresentação da experiência eucarística. Neste horizonte de "oferta comum do sacrifício e da participação comum à mesa do Senhor", em comunhão com a palavra e o sacramento, a experiência da Igreja toma corpo. Desta forma, ela não se deixa fechar numa "prática de funcionários assediados", o que trairia não apenas o munus episcopal, mas o próprio sentido do ministério ordenado. Permanecer orientados por aquilo que propõe a IGMR - para enfrentar o desafio de um tempo tão surpreendente e desconcertante - parece-me a única maneira de realmente ter presente, seja uma "mínima unidade" de ternura eclesiástica, seja um "mínimo episcopal" de competência eucarística. Depois da pandemia procuremos, pelo menos, não nos distanciar do que diz a IGMR, isto é, de pelo menos não dispensar da referência que ela nos propõe. E de recomeçar tudo a partir daí.

\section{Referências Bibliográficas}

CNBB. As introduções gerais dos livros litúrgicos. São Paulo: Paulus, 2003. MISSAL ROMANO. São Paulo: Paulinas, 1992, $2^{\mathrm{a}}$ ed. PIO X, Papa. Carta Encíclica Vehementer Nos. Roma: Libreria Editrice Vaticana, 1906.

7 Na versão português Brasil, n.62. 